\title{
Singapore attracts foreign talent
}

$\triangle$ ttracting "foreign talent" to Singapore is Aa high-profile government policy. In addition to its population of almost 3 million, there are more than 300,000 foreign workers in Singapore, including many highly educated people. "Science and technology people are particularly welcome," according to Chong Lit Cheong, executive director of the National Science and Technology Board (NSTB).

Some locals are concerned about the competition for jobs. But government officials constantly stress publicly the importance of developing the right skills for the whole country's future benefit.

Despite economic uncertainty, Singapore is expanding its universities and setting up new research institutes. It plans to double the number of postgraduate students at universities by the end of the century, and wants to develop into the education hub of the region. It aims to build a pool of qualified people to power its industry into the next century and to attract multinational companies to set up research and development centres on the island.

\section{Critical mass}

The Institute of Molecular and Cell Biology (IMCB), set up in 1987, has helped to put Singapore on the international research map. It has attracted many high-calibre researchers, expanding from a group of 38 scientists to a research staff of 250 . Its main research areas include cell regulation, functional genomics, immunology, virology and drug discovery, and its researchers have built an impressive publication record by any standards. "Singapore is trying to develop a credible critical mass of people," says Chris Tan, director of the institute.

In the wake of IMCB's success, a string of institutes have been founded in Singapore, including the Institute of Molecular Agrobiology (IMA) established in 1995; the Bioinformatics Center in 1996; the Institute of Materials Research and Engineering in 1997; the Cancer Therapeutics Research Group this year; and the Singapore Synchrotron Light Source, which should be operational by next year. The IMA has just moved into a new building on the campus of the National University of Singapore and has 10 groups working on basic and applied research. It hopes to expand its research staff from 150 to 250 over the next three years, and is looking for outstanding candidates. Many other institutes as well as the IMCB are currently looking for recruits.

According to government figures, there are about 4,000 research scientists in Singapore (excluding technicians), of whom 40 per cent are foreign. One of the NSTB's main

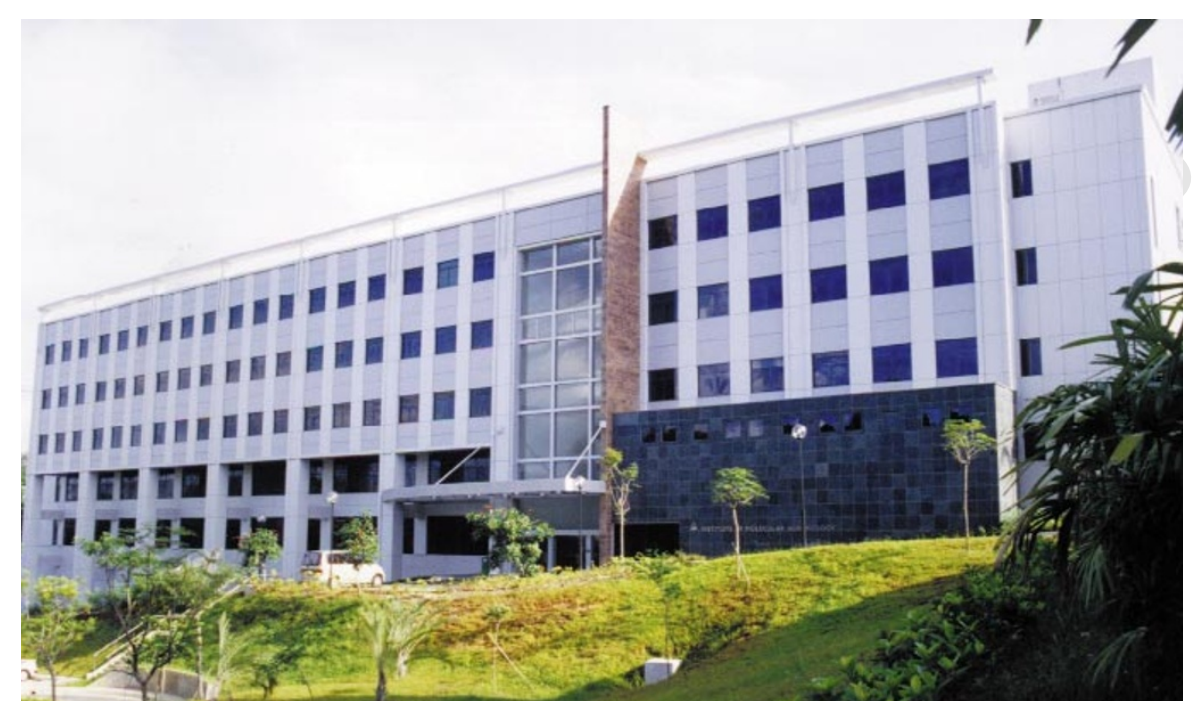

Looking to recruit 100 ‘outstanding' staff: Singapore's Institute of Molecular Agrobiology.

objectives is to encourage the development of Singapore's human resources and the recruitment of overseas researchers for industry and the research institutes. "If you have the right skills you are always welcome," says Cheong. The board has four schemes targeted at recruiting researchers from overseas. Researchers looking for work in Singapore should send their CVs, indicating their areas of interest, to the NSTB database (www.nstb.gov.sg/career). The board matches candidates with companies and institutes.

The board also has a foreign researchers' programme to assist companies in the recruitment of experienced foreign researchers, providing 50 per cent funding of recruitment by helping with relocation costs, salaries and housing allowances for up to two years. There are also postdoctoral and post-masters' fellowships to attract foreign researchers to the universities and institutes in Singapore. These researchers, mainly from mainland China, are expected to move on to industry after two years.

\section{Magnet for talent}

The economic crisis in the region has meant job cuts for production staff at semiconductor manufacturers in Singapore, but there is still a shortage of highly qualified people, especially in information technology. Many pharmaceutical companies, including GlaxoWellcome, Becton-Dickinson, Baxter and Rhone-Poulenc Rorer, have research programmes in Singapore, and biotechnology and life-science companies are also setting up facilities. Perkin-Elmer set up a plant for DNA thermal cycles, machines that amplify DNA using PCR technology, in Singapore this year.

The NSTB launched a 'magnet' pro- gramme called the Temasek Professorship last year. Temasek is the ancient name for Singapore in Malay. The idea is to target individuals in areas in which Singapore wants to develop, and hire them to head or start laboratories. These areas include biological sciences, mathematics, semiconductors and data storage. Singapore plans to recruit between 20 and 30 Temasek professors and has allocated a budget of $S \$ 150$ million (US\$89 million).

The professorships will be for between three and five years but the chosen individuals will be required to spend only 50 per cent of their time in Singapore. The first professor has already been recruited from the United Kingdom but the board says recruitment "is not an easy process". It has set up a steering committee to identify key people. The benefits on offer are substantial and, according to university officials, a whole team of researchers will be funded if necessary.

The Nangyang Technological University, which has recruited the first Temasek professor (a specialist in precision engineering), recruits 150 postdoctoral fellows every year (www.ntu.ac.sg). It has set up several new centres, according to Hong Siang Tan, director of research at the university. These include a biomedical engineering centre, launched in April last year, which has dozens of big projects in progress.

The National University of Singapore is planning a Tropical Marine Science Institute, according to Chang-Chieh Hang, the deputy vice-chancellor. The institute will be set up on St John's Island and will conduct research into marine biotechnology, oceanography, offshore engineering and tropical fish farming. The university is looking for a director for the institute, which will have between 150 and 200 research staff. 